\title{
Framework dos cenários de risco no contexto da implantação de uma refinaria de petróleo em Pernambuco
}

\author{
Risks scenarios frameworks in the context \\ of an oil refinery installation at Pernambuco State
}

\author{
Aline do M onte Gurgel ${ }^{1}$ \\ Ana Catarina Leite Veras M edeiros ${ }^{1}$ \\ Paloma Corrêa Alves ${ }^{1}$ \\ José M arcos da Silva ${ }^{1}$ \\ IdêGomes Dantas Gurgel ${ }^{1}$ \\ Lia Giraldo daSilva Augusto ${ }^{1}$
}

${ }^{1}$ Centro de Pesquisa Aggeu M agalhães, Fundação Oswaldo Cruz, Núcleo de Estudos em Saúde Coletiva. Av. Professor Moraes Rego s/n, Cidade Universitária. 50670-420 Recife PE. alinemgurgel@hotmail.com
Abstract The magnitude of the environmental and social problems due to urbanization, industrialization and exhaustion of natural resources has shown an increase in the impact on health and environment. Paradoxically, the consumption patterns demand for the expansion in the industrial production based on the exploitation of the non-renewable resources, which technological risks, especially from the petrochemical industry, have put difficulties on the risk control and health surveillance. The petroleum refining is an activity potentially damageable to the environment and human health, particularly to workers. The main objective of this study was to characterize the scenarios of risk to environmental health due to an oil refinery installation in the Metropolitan Region of Recife (Pernambuco). Based on secondary data and literature review, a Social Reproduction M atrix was made contextualizing the problems in the biological, consciousness and conduct, economic, policy and ecological dimensions, enabling to presume the risks to support the health surveillance development and organization in the state, with intersectoriality, social participation, and ableto intervene on risks and prevent diseases among the workers and people in the territory.

Key words Oil refinery, Environmental risks, Health risks, Environmental health, Social reproduction matrix
Resumo A magnitudedos problemas socioambientais relacionados à urbanização, industrialização e esgotamento de recursos naturais tem impacto crescente sobre a saúde e o ambiente. Paradoxalmente, os padrões de consumo demandam a ampliação da produção industrial, baseada na exploração de recursos não renováveis, cujos riscos tecnológicos, particularmente os da indústria petroquímica, impõem dificuldades reais às me didas de controle evigilância à saúde. 0 refino de petróleo é uma atividade potencialmente danosa ao ambiente e à saúde humana, particularmente aos trabalhadores. Esse estudo objetivou caracterizar os cenários de risco para a saúde ambiental decorrentes da instalação de uma refinaria de pe tróleo na Região M etropolitana de Recife (Pernambuco). Com base em dados secundários e re ferências da literatura, construiu-se uma matriz de reprodução social para contextualizar os problemas nas dimensões biológica, da consciência e conduta, econômica, política e ecológica, permitindo presumir riscos, com vista a subsidiar o desenvolvimento e a organização das ações de vigilância em saúde no Estado, articuladas inter setorialmente, com participação social, capazes de intervir sobre os riscos e evitar o adoecimento dos trabalhadores e da população nesse território.

Palavras-chave Refinaria de petróleo, Riscos ambientais, Riscos à saúde, Saúde ambiental, $M$ atriz de reprodução social 
Introdução

No contexto urbano brasileiro, os problemas ambientais se acumulam erepresentam situações de risco, com impactos crescentes na qualidade do ar, da água, do solo e na saúde da população. As regiões urbano-industriais destacam-se pela infraestrutura básica precária e degradação social, associadas à escassez de recursos naturais para produção e consumo ${ }^{1}$.

A despeito da magnitude dos problemas socioambientais relacionados à urbanização, industrialização e esgotamento de recursos naturais, paradoxalmente, os padrões de consumo demandam o aumento da produção industrial com base na intensificação da exploração da natureza.

N esse cenário, a indústria petroquímica ampliou sua produção, dando ao petróleo um papel central como fornecedor de energia ematéria-prima para a manufatura de inúmeros bens de consumo². Apesar de sua produção estar caminhando para a fase de declínio ${ }^{3}$, o petróleo ainda é a principal fontedeenergia no mundo, representando $43 \%$ daenergiaconsumida no planetaem $2002^{4}$.

Por ser uma mistura complexa de compostos orgânicos, com predominância de hidrocarbonetos e frações menos representativas de enxofre, nitrogênio, oxigênio e metais como vanádio, níquel, sódio, cálcio, cobreeurânio, o petróleo permite inúmeras sínteses ${ }^{5}$. 0 máximo aproveitamento do potencial energético do petróleo é obtido quando os hidrocarbonetos que o compõem são separados mediante um processo de beneficiamento conhecido como refino, resultando em diferentes produtos².

Para aumentar a oferta e garantir a autossuficiência do mercado interno brasileiro para alguns derivados de petróleo, diminuir a importação de óleo diesel e petróleo leve e reduzir a dependência da América do Sul no abastecimento de energia, o Brasil terá uma nova refinaria com sede em Pernambuco ${ }^{6}$, que será instalada no Complexo Industrial Portuário de Suape (CIPS) ou Complexo Industrial Portuário Governador Eraldo Gueiros, localizado na Região M etropolitana do Recife, entre os municípios de Cabo de Santo Agostinho e I pojuca?

A indústria de petróleo, em todas as fases do processo produtivo, tem potencial para causar impactos sobre 0 ambiente e a saúde das populações, em especial à saúde dos trabalhadores, em função dos riscos específicos no ambiente de trabalho ${ }^{8}$. Sabe-se que os hidrocarbonetos aromáticos presentes no petróleo, tais como o benzeno, tolueno exileno (BTX), têm efeitos mutagênicos, carcinogênicos, teratogênicos ${ }^{9}$, neurotóxicos ${ }^{10} \mathrm{e}$ apresentam tóxico agudo, sendo mielotóxicos ${ }^{11}$.

As refinarias de petróleo constituem uma das atividades humanas de maior potencial poluidor. Elas consomem grandes quantidades de água e de energia, produzem grandes quantidades de despejos líquidos, liberam diversos gases nocivos para a atmosfera e produzem resíduos sólidos de difícil tratamento e disposição. Em decorrência desses fatos, as refinarias muitas vezes são grandes degradadoras do ambiente, pois têm potencial para afetar 0 ar, a água, o solo e, consequentemente, todo o meio biótico em seu entorno? ${ }^{2}$.

Também são frequentes os acidentes de trabalho edeengenharia, como explosões, vazamentos, disposição inadequada de resíduos e transportede produtos perigosos ${ }^{10}$. Entre 1945 e 1991, o Brasil ocupou a segunda posição entre os dez países com maior número de acidentes químicos. Esses acidentes catastróficos estão associados à existência devulnerabilidades sociais einstitucionais nos contextos local, regional e nacional ${ }^{12}$.

A compreensão da natureza complexa dos problemas socioambientais e da múltipla determinação social da saúde mostra a necessidade de uma abordagem própria aos sistemas complexos. Cancio ${ }^{13}$ destaca a necessidade de abordar os problemas do desenvolvimento de forma sistêmica, interdisciplinar e intersetorial em todos os níveis da organização social.

Samaja ${ }^{14}$ considera o contexto de desenvolvimento humano segundo a reprodução social. Os processos de reprodução social são interdependentes e podem agrupar-se em quatro dimensões: a reprodução biocomunal; da autoconsciência e da conduta humana (comunal-cultural); a econômica (societal) e a ecológica-política. As informações de cada uma dessas dimensões podem ser organizadas em uma matriz de dados para um modelo compreensivo ${ }^{15}$.

A reprodução biocomunal considera que a sociedade se organiza no dia a dia como um organismo vivo, resultando em redes de interações estruturadas; a reprodução da autoconsciência e da conduta humana se refere ao ser humano como produtor da cultura, ou seja, de redes simbólicas de elaboração e transmissão de experiências e apren dizagem; a reprodução econômica se refere aos processos pelos quais os seres humanos devem produzir seus meios de vida material e a reprodução ecológico-política se reporta ao processo de interdependência mediada pelos seres humanos entre as condições ambientais, as relações societais, as relações comunais-culturais e as relações biocomunais ${ }^{16}$. 
Esse modelo interpretativo permite apreender a globalidade do problema e orientar intervenções nos seus diferentes níveis com as suas interconexões causais ${ }^{17}$, possibilitando uma contextualização e a ruptura com o modelo mono ou multicausal do processo saúde-doença ${ }^{15}$.

Considerando os impactos da atividade de refino de petróleo, esse trabalho objetivou caracterizar os cenários de risco para a saúde e o ambiente decorrentes da instalação de uma refinaria de petróleo em Pernambuco.

\section{Procedimentos metodológicos}

Esse estudo pautou-se pela utilização de dados secundários e referências da literatura, para caracterizar o contexto ambiental, político, econômico e social relacionado à refinaria. Foram utilizados dados disponibilizados pelo IBGE, Anvisa, Condepe/Fidem, CPRH, FIEPE, Sectma, SEPLAN-PE, Petrobras, Cerest/Cabo, Datasus, SIM , SINAM, SIH, SIAB, além de livros, monografias, dissertações, teses, jornais, revistas de difusão, periódicos indexados (M edline, Lilacs, Scielo), informações obtidas no workshop "Conhecendo a RefinariaAbreu eLima", no Estudo del mpacto Ambiental e Relatório de Impacto Ambiental (EIA/RIM A) da refinaria, assim como a legislação ambiental, os planos de desenvolvimento e zoneamento deSuapee as políticas deintegração energética da América do Sul. A busca de informações nessas fontes de dados foi orientada para a construção da matriz de dados de acordo com o seu marco teórico ${ }^{16}$, buscando variáveis com maior força explicativa.

Foram utilizadas variáveis para: (1) a caracterização dos municípios do Cabo deSanto Agostinho e I pojuca e da cadeia produtiva do refino do petróleo; (2) a identificação dos impactos socioeconômicos da operação da refinaria na re gião e (3) os riscos à saúde e ao ambiente decorrentes da exposição ao petróleo e seus derivados.

Para examinar com mais profundidade os aspectos políticos e ambientais da categoria de análise de reprodução ecológico-política, esta foi desdobrada nas dimensões política e ecológica.

$\mathrm{Na}$ construção da matriz de dados, considerou-se os agravos decorrentes do esgotamento sanitário e efluentes industriais como problemas de reprodução biocomunal. Os relacionados à consciência eà conduta foram aqueles relacionados ao cuidado da saúde e do ambiente (serviços de saúde, saneamento e organizações da sociedade civil). Os problemas no âmbito do merca- do de trabalho e da família (pobreza, empregabilidade, migração) constituíram os dados da reprodução econômica. As situações relacionadas às políticas públicas, como vulnerabilidades institucionais e sociais, para promoção da saúde, como conflitos sociais, padrões de produção-consumo e exclusão social foram integradas à categoria da reprodução política. Para a dimensão da reprodução ecológica, foram consideradas as potenciais situações de risco da intensa urbanização, as características do refino do petróleo e seus impactos.

As categorias de análise e as variáveis descritoras dos problemas foram organizadas em quadros que também apoiaram a construção da matriz de dados.

\section{Resultados ediscussões}

A Refinaria do Nordeste S/A (REFINE, RNEST ou Refinaria General José I gnácio Abreu eLima) éum empreendimento pretendido pela Petrobras em parceria com a Petróleos Venezuela (PDV$S A)^{18}$. Com capacidade para refinar 200.000 barris de petróleo por dia, dos quais 100.000 serão de petróleo brasileiro, e produzir 60.000 barris de derivados de petróleo por dia, 5.000 já na primeira etapa, a REFINE se destinará à produção de GLP, nafta, gasolina, querosene, óleo diesel e óleo combustível. A previsão é que a REFINE comece a operar em $2011^{19}$.

Os danos ambientais decorrentes da instalação e operação de uma refinaria provêm tanto da matéria-prima utilizada e de seus derivados quanto do refino, que é uma atividade impactante devido à grande variedade de processos e operações utilizados na extração das fraçõe ${ }^{19}$. Muitos dos compostos utilizados e gerados em refinarias saem das unidades de processamento sob a forma de emissões atmosféricas, efluentes líquidos ou resíduos sólidos.

Os efluentes líquidos consistem em águas utilizadas no processamento, esgotos sanitários e chuva. As águas de processo entram em contato direto com o óleo e são muito contaminadas e passam por tratamento. As unidades de tratamento de efluentes são também fonte significativa de emissões atmosféricas e resíduos sólidos em refinarias ${ }^{2}$ que requerem medidas de engenharia para o controle de poluição.

As emissões atmosféricas incluem emissões fugitivas dos compostos voláteis presentes no óleo cru e nas suas frações, das unidades de processo, e geradas pela queima de combustíveis na 
produção ${ }^{19}$. Os poluentes tipicamente gerados incluem hidrocarbonetos voláteis, monóxido de carbono (CO), óxidos de enxofre $\left(\mathrm{SO}_{\mathrm{x}}\right)$, óxidos de nitrogênio $\left(\mathrm{NO}_{x}\right)$, material particulado, amônia $\left(\mathrm{NH}_{3}\right)$, sulfeto de hidrogênio $\left(\mathrm{H}_{2} \mathrm{~S}\right)$, metais, ácidos exaustos e compostos orgânicos tóxicos.

A poluição sonora é causada principalmente pelo funcionamento de equipamentos, como turbinas e motores, e pela operação de veículos de transporte durante as fases de instalação e operação da refinaria².

Os resíduos sólidos são gerados durante 0 processo de refino, operações de manuseio do petróleo e no tratamento de efluentes, normalmente sob a forma de lamas, cinzas de incineradores e borras de filtração. Os constituintes típicos incluem metais, hidrocarbonetos aromáticos, amônia eácido sulfídrico².

Importante resíduo sólido, o coque verde de petróleo, embora seja um subproduto do processo de refino, ganhou valor comercial e passou a ser comercializado como combustível em fornos e caldeiras, sendo utilizado em cimenteiras, indústrias de cerâmica, calcinadoras de gesso e outras. 0 coque verde possui em sua composição elementos tóxicos presentes no petróleo, tais como enxofre, metais pesados e hidrocarbonetos voláteis. A sua utilização como fonte energé tica gera, dentre outras substâncias, dioxinas e furanos, reconhecidas pela O rganização Mundial de Saúde como carcinogênicos ${ }^{20}$.

A exposição humana pode ser ocupacional ou ambiental, quando esses compostos são liberados mediante vazamentos, emissões fugitivas, disposição inadequada de resíduos ou acidentes. Hidrocarbonetos aromáticos e metais pesados ainda podem contaminar animais e plantas, contaminando água e alimento $\mathrm{s}^{21}$ que, se consumidos, podem provocar intoxicação química. As principais consequências dessa poluição são mostradas nos Q uadros 1 e 2 .

Quadro 1. Efeitos à saúde e ao ambiente decorrentes da poluição sonora, emissões atmosféricas, resíduos sólidos e efluentes líquidos produzidos na fase de instalação da REFINE.

\begin{tabular}{|c|c|c|c|}
\hline \multirow[b]{2}{*}{ Origem } & \multicolumn{3}{|c|}{ Efeitos na fase de instalação } \\
\hline & Poluentes & Saúde & M eio ambiente \\
\hline $\begin{array}{l}\text { Poluição } \\
\text { Sonora }\end{array}$ & Poluição sonora & $\begin{array}{l}\text { perda gradativa da audição; } \\
\text { interferência no sistema nervoso; } \\
\text { incômodo, irritação, exaustão } \\
\text { física; perturbações no sono; fadiga; } \\
\text { problemas cardiovasculares; } \\
\text { estresse; aumento da quantidade de } \\
\text { adrenalina no sangue; } \\
\text { hiperestímulo da glândula tireóide; } \\
\text { redução da eficiência do indivíduo; } \\
\text { ocorrência de acidentes }\end{array}$ & perturbação da fauna local \\
\hline $\begin{array}{l}\text { Emissões } \\
\text { atmosféricas }\end{array}$ & $\begin{array}{l}\text { CO } \\
\text { (monóxido de } \\
\text { carbono) }\end{array}$ & $\begin{array}{l}\text { dor de cabeça; dificuldade de } \\
\text { respirar; tontura; doenças } \\
\text { cardiovasculares; efeitos } \\
\text { teratogênicos no feto }\end{array}$ & $\begin{array}{l}\text { transforma-se em } \mathrm{CO}_{2} \text {, contribuindo } \\
\text { para o efeito estufa }\end{array}$ \\
\hline $\begin{array}{l}\text { Resíduos } \\
\text { sólidos }\end{array}$ & $\begin{array}{l}\text { Resíduos sólidos } \\
\text { industriais classe } \\
\text { III }\end{array}$ & $\begin{array}{l}\text { aumento da mobimortalidade por } \\
\text { doenças infecciosas e parasitárias }\end{array}$ & $\begin{array}{l}\text { aspecto estético desagradável; } \\
\text { desfiguração das paisagens; } \\
\text { contaminação da água, ar e solo; } \\
\text { risco de acidentes com animais } \\
\text { domésticos e silvestres }\end{array}$ \\
\hline $\begin{array}{l}\text { Efluentes } \\
\text { líquidos }\end{array}$ & $\begin{array}{l}\text { Efluentes de } \\
\text { esgotamento } \\
\text { sanitário }\end{array}$ & $\begin{array}{l}\text { doenças de veiculação hídrica e } \\
\text { decorrentes da ingestão de animais } \\
\text { expostos aos efluentes }\end{array}$ & $\begin{array}{l}\text { contaminação dos rios, flora e fauna } \\
\text { existentes na área, podendo levar à } \\
\text { morte desses organismos e extinção } \\
\text { de espécies mais sensíveis }\end{array}$ \\
\hline
\end{tabular}


Quadro 2. Efeitos à saúde e ao ambiente decorrentes da poluição sonora, emissões atmosféricas, resíduos sólidos e efluentes líquidos produzidos na fase de operação da REFINE.

\begin{tabular}{|c|c|c|c|}
\hline \multirow[b]{2}{*}{ Origem } & \multicolumn{3}{|c|}{ Efeitos na fase de operação } \\
\hline & Poluentes & Saúde & M eio ambiente \\
\hline \multirow[t]{10}{*}{$\begin{array}{l}\text { Emissões } \\
\text { atmosféricas }\end{array}$} & $\begin{array}{l}\text { VOCs (acetileno, } \\
\text { etano, eteno, GLP, } \\
\text { metano, propano, } \\
\text { propeno, butano) }\end{array}$ & $\begin{array}{l}\text { irritação no olhos; perda do bem-estar devido } \\
\text { ao odor; asfixia, hipóxia, parada respiratória; } \\
\text { distúrbios no SNC }\end{array}$ & $\begin{array}{l}\text { redução da visibilidade; desequilíbrio } \\
\text { ambiental; danos sobre os materiais; } \\
\text { smog fotoquímico; contribuição para } \\
\text { o efeito estufa }\end{array}$ \\
\hline & $\begin{array}{l}\text { CO } \\
\text { monóxido } \\
\text { carbono }\end{array}$ & $\begin{array}{l}\text { dor de cabeça; dificuldade de respirar; tontura; } \\
\text { doenças cardiovasculares; efeitos teratogênicos } \\
\text { no feto }\end{array}$ & $\begin{array}{l}\text { tranforma-se em } \mathrm{CO}_{2} \\
\text { contribuindo para o efeito estufa }\end{array}$ \\
\hline & $\begin{array}{l}\text { NOx } \\
\text { (óxidos de } \\
\text { nitrogênio) }\end{array}$ & $\begin{array}{l}\text { conjuntivite; tosse, irritação, lesões e distúrbios } \\
\text { sistêmicos; problemas no sistema respiratório } \\
\text { (insuficiência respiratória, bronquite, infecção } \\
\text { pulmonar, doenças respiratórias agudas, } \\
\text { pneumonias, enfisema pulmonar, edema } \\
\text { pulmonar); insuficiência cardíaca; distúrbios } \\
\text { no SNC }\end{array}$ & $\begin{array}{l}\text { danos na vegetação e solo; } \\
\text { chuva ácida; smog fotoquímico; } \\
\text { contribuição para o efeito estufa }\end{array}$ \\
\hline & $\begin{array}{l}\text { SOx } \\
\text { (óxidos de } \\
\text { enxofre) }\end{array}$ & $\begin{array}{l}\text { irritação na pele, olhos e mucosas; reações } \\
\text { alérgicas; problemas no dentes; alterações } \\
\text { metabólicas; problemas no sistema respiratório } \\
\text { (nosofaringite, pneumonia, bronquite, } \\
\text { enfisema e edema pulmonar, choque); danos } \\
\text { no sistema imunológico; distúrbios no SNC }\end{array}$ & $\begin{array}{l}\text { danos na vegetação e solo; } \\
\text { chuva ácida }\end{array}$ \\
\hline & $\begin{array}{l}\mathrm{H}_{2} \mathrm{~S} \\
\text { (gás sulfídrico) }\end{array}$ & $\begin{array}{l}\text { irritação dos olhos e vias respiratórias; } \\
\text { problemas no sistema respiratório; distúrbios } \\
\text { digestivos; distúrbios no SNC }\end{array}$ & $\begin{array}{l}\text { odor desagradável no ambiente; } \\
\text { danos na vegetação e solo }\end{array}$ \\
\hline & $\begin{array}{l}\text { Material } \\
\text { particulado }\end{array}$ & $\begin{array}{l}\text { irritação nas vias aéreas superiores; } \\
\text { agravamento da asma e da bronquite; doenças } \\
\text { respiratórias e cardíacas }\end{array}$ & $\begin{array}{l}\text { prejuízos para a agricultura; } \\
\text { danos para a vegetação e solo; } \\
\text { contaminação por metais pesados }\end{array}$ \\
\hline & $\begin{array}{l}\mathrm{NH}_{3} \\
\text { (amônia) }\end{array}$ & $\begin{array}{l}\text { lesão tissular; iritação nos olhos e vias aéreas } \\
\text { superiores; problemas respiratórios; problemas } \\
\text { cardíacos; problemas no sistema digestivo }\end{array}$ & danos na vegetação e solo \\
\hline & Benzeno & $\begin{array}{l}\text { benzenismo; alterações hematológi cas; } \\
\text { alterações neurológicas; alterações } \\
\text { cromossômicas }\end{array}$ & \multirow{3}{*}{$\begin{array}{l}\text { narcose em animais aquáticos; } \\
\text { produção de maus odores; poluição } \\
\text { da água pelo carreamento superficial } \\
\text { ou pela infiltração dos detritos para } \\
\text { os corpos hídricos; liberação de gases } \\
\text { tóxicos; poluição do ar; alterações } \\
\text { químicas do solo (impactos na biota, } \\
\text { danos à saúde humana e aos } \\
\text { organismos vivos) }\end{array}$} \\
\hline & Tolueno & $\begin{array}{l}\text { irritação na pele e nas vias aéreas superiores; } \\
\text { anemias; depressão do SNC; distúrbios } \\
\text { psíquicos; doenças neurológicas }\end{array}$ & \\
\hline & Xileno & $\begin{array}{l}\text { irritação na pele, mucosas e olhos; danos no } \\
\text { fígado; anemia; problemas no SNC }\end{array}$ & \\
\hline $\begin{array}{l}\text { Poluição } \\
\text { sonora }\end{array}$ & Poluição sonora & $\begin{array}{l}\text { perda gradativa da audição; interferência no } \\
\text { sistema nervoso; incômodo, irritação, exaustão } \\
\text { física; perturbações no sono; fadiga; problemas } \\
\text { cardiovasculares; estresse; aumento da } \\
\text { quantidade de adrenalina no sangue; } \\
\text { hiperestímulo da glândula tireóide; redução da } \\
\text { eficiência do indivíduo; ocorrência de } \\
\text { acidentes }\end{array}$ & perturbação da fauna local \\
\hline
\end{tabular}


Quadro 2. continuação

\begin{tabular}{|c|c|c|c|}
\hline \multirow[b]{2}{*}{ Origem } & \multicolumn{3}{|c|}{ Efeitos na fase de operação } \\
\hline & Poluentes & Saúde & M eio ambiente \\
\hline \multirow[t]{6}{*}{$\begin{array}{l}\text { Efluentes } \\
\text { líquidos }\end{array}$} & $\begin{array}{l}\mathrm{H}_{2} \mathrm{~S} \\
\text { (ácido } \\
\text { sulfídrico) }\end{array}$ & $\begin{array}{l}\text { conjuntivite, fotofobia, lacrimejamento e opacificação da } \\
\text { córnea; tosse, expectoração sanguinolenta, respiração } \\
\text { acelerada, espasmo brônquico, edema agudo de pulmão, } \\
\text { rinite com perda de olfato, broncopneumonia e } \\
\text { traqueobronquite); perda de apetite e de peso, náuseas; } \\
\text { prurido e vermelhidão; excitação seguida de depressão, } \\
\text { fraqueza, dor de cabeça, náuseas, vômito, } \\
\text { hiperexcitabilidade, alucinações, amnésia, irritabilidade, } \\
\text { delírios, sonolência, fraqueza, convulsões e morte }\end{array}$ & $\begin{array}{l}\text { odor desagradável no } \\
\text { ambiente; danos na vegetação } \\
\text { (necrose nas partes superiores } \\
\text { das folhas) e solo }\end{array}$ \\
\hline & $\begin{array}{l}\mathrm{NH}_{3} \\
\text { (amônia) }\end{array}$ & $\begin{array}{l}\text { lesão tissular/queimaduras - amônia líquida; } \\
\text { lacrimejamento, edema palpebral, úlcera da córnea, atrofia } \\
\text { da íris, atrofia da retina, catarata tardia e cegueira; tosse, } \\
\text { faringite, laringite, broncoespasmo, dor torácica, dispnéia, } \\
\text { traquéte, edema agudo dos pulmões, bronquite, enfisema } \\
\text { pulmonar e asma; asfixia, parada respiratória; alteração do } \\
\text { ritmo e batimentos do coração; náuseas, vômitos, sensação } \\
\text { de queimação e edema dos lábios, da boca e do nariz e } \\
\text { quando ingerida ingestão ocorrem queimaduras da boca, } \\
\text { esôfago, perfuração gástrica }\end{array}$ & $\begin{array}{l}\text { danos na vegetação (coloração } \\
\text { verde forte e pontos negros } \\
\text { necrosados nas margens das } \\
\text { folhas ) e solo; altas } \\
\text { quantidades causam } \\
\text { sufocamento } \\
\text { de peixes e floração devido a } \\
\text { super produção de algas } \\
\text { (eutrofização) }\end{array}$ \\
\hline & $\begin{array}{l}\mathrm{C}_{6} \mathrm{H}_{5} \mathrm{OH} \\
\text { (fenol/ácido } \\
\text { carbólico) }\end{array}$ & $\begin{array}{l}\text { sudorese, cefaléia, vertigens, palidez; fraqueza, tremores e } \\
\text { contrações musculares; transtornos digestivos, } \\
\text { queimaduras na boca e garganta, dor abdominal } \\
\text { acentuada, cianose; danos ao fígado; lesão renal; tosse, } \\
\text { dispnéia e parada respiratória; eritema, queimaduras } \\
\text { severas, despigmentação localizada, gangrena dos tecidos e } \\
\text { necrose; inchaço na conjuntiva, córnea esbranquiçada e } \\
\text { dolorida e perda da visão; câncer }\end{array}$ & $\begin{array}{l}\text { incêndios e explosões, além de } \\
\text { danos à fauna, à flora e à vida } \\
\text { aquática }\end{array}$ \\
\hline & $\begin{array}{l}\text { RSH } \\
\text { (mercaptans/ } \\
\text { thiol) }\end{array}$ & $\begin{array}{l}\text { Odor forte e repulsivo podendo causar náuseas, enjôos e } \\
\text { dores de cabeça; quando associado a outras moléculas é } \\
\text { altamente tóxico }\end{array}$ & $\begin{array}{l}\text { odor desagradável no } \\
\text { ambiente, danos à fauna, à } \\
\text { flora eà vida } \\
\text { aquática. }\end{array}$ \\
\hline & $\begin{array}{l}\mathrm{HCl} \\
\text { (cloreto/ } \\
\text { ácido } \\
\text { clorídrico) }\end{array}$ & $\begin{array}{l}\text { irritação, queimaduras sérias até a perda da visão; tosse, } \\
\text { queimação, edema de glote e pulomar, sufocamento; } \\
\text { descoloração dos dentes; irritação na pele, queimaduras } \\
\text { graves, dermatites, destruição dos tecidos); queimaduras } \\
\text { nas mucosas da boca e sistema digestivo - esôfago e } \\
\text { estômago- quando ingeridos podendo levar ao óbito }\end{array}$ & $\begin{array}{l}\text { poluição salina (polui rios e } \\
\text { corpos d'água alterando o pH, } \\
\text { podendo contaminar o solo, } \\
\text { afetando a flora e a fauna } \\
\text { expostos, eliminando algumas } \\
\text { espécies de animais aquáticos } \\
\text { em concentrações elevadas) }\end{array}$ \\
\hline & $\begin{array}{l}\mathrm{HCN} \\
\text { (cianeto/ } \\
\text { ácido } \\
\text { cianídrico/ } \\
\text { prússico) }\end{array}$ & $\begin{array}{l}\text { morte por anóxia e alterações no SNC, sistema } \\
\text { cardiovascular e no sistema respiratório (morte por } \\
\text { sufocamento) }\end{array}$ & $\begin{array}{l}\text { quando em contato com o ar } \\
\text { torna-se um potente } \\
\text { explosivo, causa a poluição } \\
\text { salina (eliminação de algumas } \\
\text { espécies de animais aquáticos } \\
\text { em concentrações elevadas) }\end{array}$ \\
\hline
\end{tabular}


Quadro 2. continuação

\begin{tabular}{|c|c|c|c|}
\hline \multirow[b]{2}{*}{ Origem } & \multicolumn{3}{|c|}{ Efeitos na fase de operação } \\
\hline & Poluentes & Saúde & M eio ambiente \\
\hline \multirow[t]{5}{*}{$\begin{array}{l}\text { Efluentes } \\
\text { líquidos }\end{array}$} & $\begin{array}{l}\text { Sólidos } \\
\text { dissolvidos e em } \\
\text { suspensão }\end{array}$ & sem efeitos diretos observáveis & $\begin{array}{l}\text { assoreamento dos recursos hídricos; } \\
\text { diminuição das vazões de escoamento e dos } \\
\text { volumes de armazenamento; inundações; } \\
\text { soterramento de animais e de ovos de } \\
\text { peixes; aumento da turbidez da água; } \\
\text { redução da taxa fotossintética e da } \\
\text { quantidade de oxigênio dissolvido; redução } \\
\text { do número de espécies e do número de } \\
\text { organismos que vivem no meio afetado }\end{array}$ \\
\hline & $\begin{array}{l}\text { Petróleo cru e seus } \\
\text { derivados (BTX } \\
\text { ou BTEX) }\end{array}$ & $\begin{array}{l}\text { câncer e problemas descritos para } \\
\text { os hidrocarbonetos benzeno, } \\
\text { tolueno e xileno }\end{array}$ & $\begin{array}{l}\text { redução da quantidade de luz solar } \\
\text { disponível; redução da taxa de fotossíntese, } \\
\text { morte de certos organismos (plânctons); } \\
\text { aderência do óleo nos corpos dos animais } \\
\text { (mamíferos, peixes, pássaros e crustáceos), } \\
\text { causando prejuízos à saúde ou morte }\end{array}$ \\
\hline & $\begin{array}{l}\text { Efluentes de } \\
\text { esgotamento } \\
\text { sanitário }\end{array}$ & $\begin{array}{l}\text { doenças de veiculação hídrica e } \\
\text { decorrentes da ingestão de animais } \\
\text { expostos aos efluentes }\end{array}$ & $\begin{array}{l}\text { contaminação dos rios, flora e fauna, } \\
\text { podendo haver morte desses organismos e } \\
\text { extinção de espécies mais sensíveis }\end{array}$ \\
\hline & $\begin{array}{l}\text { M etais } \\
(\mathrm{Cd}, \mathrm{Cr}, \mathrm{Cu}, \mathrm{Pb} \\
\mathrm{Ni}, \mathrm{Zn}, \mathrm{P})\end{array}$ & $\begin{array}{l}\text { intoxicação causada por ingestão } \\
\text { dos animais expostos (crustáceos e } \\
\text { peixes) }\end{array}$ & $\begin{array}{l}\text { intoxicação dos organismos aquáticos, tais } \\
\text { como moluscos, crustáceos, oligoquetos e } \\
\text { algas; modificações severas na fauna e flora } \\
\text { aquáticas; redução do número de espécies e } \\
\text { eliminação das mais sensíveis }\end{array}$ \\
\hline & $\begin{array}{l}\mathrm{NAOH} \\
\text { (soda cáustica) }\end{array}$ & $\begin{array}{l}\text { distúrbios respiratórios, } \\
\text { neurológicos, musculares, digestivos } \\
\text { e dermatológicos; irritação nos } \\
\text { olhos e nas mucosas }\end{array}$ & $\begin{array}{l}\text { contaminação de esgotos, rios, córregos e } \\
\text { outras correntes de água; danos à flora e } \\
\text { fauna; poluição do ar e do solo }\end{array}$ \\
\hline \multirow{4}{*}{$\begin{array}{l}\text { Resíduos } \\
\text { sólidos }\end{array}$} & BTX ou BTEX & $\begin{array}{l}\text { mesmos danos descritos para as } \\
\text { emissões atmosféricas }\end{array}$ & $\begin{array}{l}\text { mesmos danos descritos para as emissões } \\
\text { atmosféricas }\end{array}$ \\
\hline & Enxofre & $\begin{array}{l}\text { irritação na pele, olhos e mucosas; } \\
\text { reações alérgicas; problemas no } \\
\text { dentes; alterações metabólicas; } \\
\text { danos no sistema imunológico; } \\
\text { problemas no sistema respiratório } \\
\text { (nosofaringite, pneumonia, } \\
\text { bronquite, enfisema e edema } \\
\text { pulmonar, choque) }\end{array}$ & $\begin{array}{l}\text { chuva ácida; danos à vegetação; alterações } \\
\text { químicas do solo; poluição do ar }\end{array}$ \\
\hline & $\begin{array}{l}\text { Metais }(\mathrm{Cd}, \mathrm{Cr}, \mathrm{Cu} \text {, } \\
\mathrm{Pb}, \mathrm{Ni}, \mathrm{Zn}, \mathrm{P})\end{array}$ & $\begin{array}{l}\text { distúrbios no SN C; intoxicação por } \\
\text { ingestão de alimentos } \\
\text { contaminados com metais pesados }\end{array}$ & $\begin{array}{l}\text { contaminação de animais e vegetação; } \\
\text { supressão da vegetação; alterações químicas } \\
\text { do solo }\end{array}$ \\
\hline & $\begin{array}{l}\text { Resíduos sólidos } \\
\text { industriais } \\
\text { classe III }\end{array}$ & $\begin{array}{l}\text { aumento da morbimortalidade por } \\
\text { doenças infecciosas e parasitárias }\end{array}$ & $\begin{array}{l}\text { aspecto estético desagradável, desfiguração } \\
\text { das paisagens; contaminação da água, ar e } \\
\text { solo; degradação/restrição do uso do solo; } \\
\text { risco de acidentes com animais domésticos e } \\
\text { silvestres }\end{array}$ \\
\hline
\end{tabular}


Em refinarias, existeo risco de ocorrerem acidentes ampliados, que transpõem a escala espacial da indústria, atingindo seu entorno, com efeitos ecotoxicológicos decurto, médio elongo prazos, resultando no aumento do número e da gravidade dos eventos ${ }^{22}$. Além da poluição ambiental, existe o risco de explosão ou incêndio ${ }^{23}$.

0 modelo de desenvolvimento adotado pelo Brasil, que combina concentração de capital, ex- ploração da mão-de-obra e abandono ou omisão do poder público, amplia as situações de risco para a saúde ${ }^{12}$. No Quadro 3, os dados obtidos foram sistematizados segundo a categoria de análise da reprodução social e em suas subcategorias.

Analisando a matriz de reprodução social (Quadro 3), no âmbito da reprodução biológica, observa-se que, em 2006, as doenças infecciosase

Quadro 3. Matriz de reprodução social.

\begin{tabular}{|c|c|c|c|c|}
\hline $\begin{array}{c}\text { Reprodução } \\
\text { biológica }\end{array}$ & $\begin{array}{c}\text { Reprodução da } \\
\text { consciência e da } \\
\text { conduta }\end{array}$ & $\begin{array}{c}\text { Reprodução } \\
\text { econômica }\end{array}$ & Reprodução política & Reprodução ecológica \\
\hline $\begin{array}{l}\text { 1. Problemas } \\
\text { da } \\
\text { reprodução } \\
\text { biológica no } \\
\text { âmbito da } \\
\text { sociedade } \\
\text { - agravos } \\
\text { decorrentes } \\
\text { do } \\
\text { saneamento } \\
\text { básico } \\
\text { inadequado } \\
\text { - agravos } \\
\text { decorrentes } \\
\text { dos efluentes } \\
\text { industriais } \\
\text { sólidos, } \\
\text { líquidose } \\
\text { gasosos }\end{array}$ & $\begin{array}{l}\text { 1. Problemas da } \\
\text { socialização no } \\
\text { âmbito comunal/ } \\
\text { societal } \\
\text { - problemas do } \\
\text { âmbito dos } \\
\text { distritos/bairros, } \\
\text { dos serviços de } \\
\text { saúde e de } \\
\text { saneamento e de } \\
\text { outras } \\
\text { organizações da } \\
\text { sociedade civil: } \\
\text { a. pouca } \\
\text { participação da } \\
\text { comunidade em } \\
\text { atividades } \\
\text { solidárias } \\
\text { b. atitude passiva/ } \\
\text { paternalista da } \\
\text { população para } \\
\text { melhorar sua } \\
\text { situação } \\
\text { habitacional e do } \\
\text { distrito/bairro } \\
\text { c. falta de espaços } \\
\text { paradiversão } \\
\text { d. falta de } \\
\text { qualificação } \\
\text { profissional } \\
\text { e. baixo nível de } \\
\text { escolaridadee } \\
\text { ausência de } \\
\text { programa de } \\
\text { educação sanitária/ } \\
\text { ambiental }\end{array}$ & $\begin{array}{l}\text { 1. Problemas do âmbito } \\
\text { político-jurídico } \\
\text { - mudanças de modelos } \\
\text { e políticas econômico- } \\
\text { sociais } \\
\text { a. falta de serviços } \\
\text { básicos e assistenciais } \\
\text { b. modelo de } \\
\text { desenvolvimento } \\
\text { econômico e } \\
\text { tecnológico brasileiro } \\
\text { c. distribuição não } \\
\text { equânime do } \\
\text { Investimento Social } \\
\text { 2. Problemas no âmbito } \\
\text { da sociedade civil } \\
\text { a. inserção no mercado } \\
\text { de trabalho } \\
\text { b. reestruturação } \\
\text { produtiva } \\
\text { c. fechamento de } \\
\text { pequenas Indústrias } \\
\text { 3. Problemas do âmbito } \\
\text { familiar } \\
\text { - pobreza e desocupação } \\
\text { a. renda familiar } \\
\text { insuficiente } \\
\text { b. desemprego, } \\
\text { subemprego } \\
\text { criminalidade } \\
\text { c. migração (individual } \\
\text { ou familiar) por } \\
\text { problemas de trabalho } \\
\text { d. trabalho de crianças e } \\
\text { adolescentes }\end{array}$ & $\begin{array}{l}\text { 1. Problemas do âmbito } \\
\text { político: políticas públicas } \\
\text { a. debilidade das } \\
\text { instituições } \\
\text { b. falta de ação social sobre } \\
\text { o ambiente } \\
\text { c. uso inadequado do } \\
\text { dinheiro público } \\
\text { d. mal uso da informação } \\
\text { e. problemas de acesso aos } \\
\text { serviços de saúde e } \\
\text { saneamento } \\
\text { f. déficit dos serviços } \\
\text { públicos } \\
\text { f.1 serviços de saúde } \\
\text { f.2 serviços de saneamento } \\
\text { f.3 serviço de atenção ao } \\
\text { trabalhador - CEREST } \\
\text { g. Indefinição ou não } \\
\text { cumprimento dos papéis } \\
\text { institucionais } \\
\text { h. Déficit habitacional } \\
\text { 2. Problemas do Âmbito da } \\
\text { Sociedade Civil } \\
\text { M udanças Sociais } \\
\text { a. Organização social } \\
\text { b. Padrões de consumo } \\
\text { c. Conflitos de Classe } \\
\text { d. Reelaboração da cultura } \\
\text { em decorrência de } \\
\text { processosmigratórios } \\
\text { e. Redução dos níveis de } \\
\text { cidadania } \\
\text { f. Exclusão social } \\
\text { aliana }\end{array}$ & $\begin{array}{l}\text { 1. Problemas da região } \\
\text { socioambiental } \\
\text { - urbanização acelerada em } \\
\text { consequência da instalação da } \\
\text { refinaria: } \\
\text { a. degradação ambiental e } \\
\text { habitacional } \\
\text { b. precariedade das habitações } \\
\text { c. migração } \\
\text { d. abastecimento de água } \\
\text { inadequado } \\
\text { e. esgotamento sanitário } \\
\text { insuficiente } \\
\text { f. Problemas de resíduos } \\
\text { sólidos domésticos } \\
\text { - Refino e transporte do } \\
\text { petróleo bruto e seus derivados } \\
\text { a. Problemas de efluentes } \\
\text { industriais: resíduos sólidos, } \\
\text { efluentes líquidos e emissões } \\
\text { atmosféricas } \\
\text { b. Contaminação do solo por } \\
\text { agentes poluidores - lixo } \\
\text { comum, petróleo e seus } \\
\text { derivados, com consequente } \\
\text { agravamento das alterações } \\
\text { pedológicas } \\
\text { c. carreamento de } \\
\text { contaminantes para cursos } \\
\text { d'água superficiais e eventual } \\
\text { contaminação do lençol } \\
\text { freático } \\
\text { d. modificação da qualidade } \\
\text { do ar } \\
\text { e. ecossistemas } \\
\text { comprometidos: destruição } \\
\text { fauna e flora } \\
\text { f. sobrecarga/inadequação da } \\
\text { infra-estrutura viária local }\end{array}$ \\
\hline
\end{tabular}


parasitárias, geralmenteassociadas ao saneamento inadequado, representaram a terceira maior causa de internação hospitalar no município de Cabo de Santo Agostinho (SIH/SUS) e a quarta causa de mortalidade em I pojuca (SIM/SUS). Com a implantação da refinaria e de outras indústrias, surgem novas situações de riscos e novas formas de adoecer e morrer, resultando em um duplo perfil demorbimortalidadee, consequentemente, na sobrecarga dos serviços de saúde, já insuficientes para atender a demanda atual.

Em relação ao saneamento, em ambos os municípios, há extensas áreas urbanas sem abastecimento de água ou abastecidas sob regime de racionamento enão há um sistema de tratamento adequado para os esgotos. A coleta convencional dos resíduos sólidos é realizada com baixa eficiência, não há coleta seletiva estruturada e a destinação final dos resíduos se dá em lixões nos dois municípios ${ }^{24}$. Sem a implementação de meIhorias, a refinaria agravará esses problemas.

Os serviços de saúde de ambos os municípios não têm capacidade instalada e recursos humanos suficientes para atender à atual demanda, especialmenteo Centro de Referência em Saúde do Trabalhador (Cerest) regional, que atualmenteatendedozemunicípios do estado, cobrindo 508.536 habitantes. Com a instalação de novos empreendimentos, será necessária a ampliação e capacitação da rede.

No tocante aos problemas relacionados à reprodução da consciência econduta, evidencia-se a pouca participação social para a discussão e resolução dos problemas locais e defesa dos interesses da população, a exemplo do que ocorreu na audiência pública realizada para discussão do Estudo de Impacto Ambiental (EIA) da REFINE, na qual não houve qualquer contestação para a instalação do empreendimento, mesmo diante de flagrantes insuficiências do EI ${ }^{25}$. Há que se considerar a tradição rural na região, a história do coronelismo da cana-de-açúcar, a presença de pescadores tradicionais e a recente vocação turística local devido às praias do litoral sul do estado. Todo esse contexto reúne condições para não haver um movimento sindical forte ou mobilização social. Ao contrário, a promessa desenvolvimentista, de geração de emprego e as frentes de capacitação e de especulação imobiliária são o grande trunfo para criar uma atmosfera pouco reivindicativa euma baixa presença do setor público regulador.

A taxa de analfabetismo da população émuito alta, sendo de $34,2 \%$ em Ipojuca e $23,4 \%$ no Cabo de Santo Agostinho, de acordo com o cen- so $2000^{26}$. A baixa escolaridade reflete a pobreza e pode explicar os fatores que contribuem para a mesma, e mesmo com a atual oferta de qualificação profissional, dificilmente a população local alcançará postos com melhores remunerações, quepedem mão-de-obra especializada. Esta perspectiva poderá reproduzir situaçõesocorridas em outros pólos industriais do país, onde após o período de instalação industrial, os trabalhadores menos qual ificados permanecem nas periferias da cidade, ampliando as desigualdades sociais.

$\mathrm{N}$ as situações de risco relacionadas ao contexto econômico, destacam-se problemas decorrentes derenda insuficiente, com $48,7 \%$ dos chefes de família do Cabo de Santo Agostinho e $55,5 \%$ dos de I pojuca ganhando até um salário mínimo ${ }^{26}$ e a desocupação, em que $15,8 \%$ das famílias de Ipojuca e 17,4\% do Cabo de Santo Agostinho vivem sem renda alguma ${ }^{27}$. Essa situação leva ao aumento da criminalidade, do trabalho infantil eda emigração eserá agravada pelo largo contingente populacional que migrará para o território estratégico de Suape em busca de emprego. A poluição e o risco de acidente poderão reduzir a atividade turística, gerando queda nos lucros e desemprego.

Também é evidente a adoção do modelo desenvolvimentista em detrimento do desenvolvimento sustentável. A pesar da significativa riqueza a ser gerada por esses territórios, a distribuição da renda não será equitativa e as condições de vida e de trabalho serão precarizadas.

A instalação de novos empreendimentos como a refinaria irá reconfigurar o território ${ }^{19}$. Isso implica uma reestruturação produtiva, o fechamento de pequenas indústrias e a redução ou extinção de várias atividades de subsistência, como a agricultura e a pesca, levando a uma descaracterização sociocultural dessas populações pela perda das atividades produtivas com as quais seidentificavam.

Quanto à reprodução política, há insuficiência de políticas públicas nos três níveis de governo e baixa capacidade de atuação das vigilâncias, falta de rigor nas legislações ambi entais e trabaIhistas, fragilidade de políticas intersetoriais, falta de uma política de habitação nos municípios integrada à política de desenvolvimento urbano e a autossuficiência organizacional do CIPS não vislumbra o compartilhamento de responsabilidades com os municípios de Cabo el pojuca, expondo os municípios a um crescimento desordenado e agravamento do déficit habitacional.

A migração para o território estratégico de Suape e a construção dos empreendimentos em 
territórios tradicionalmente habitados pela população local promoverão pressões migratórias, com consequente descaracterização sociocultural.

Na reprodução ecológica, já se observam problemas decorrentes da urbanização acelerada, da implantação e operação da refinaria e armazenamento e transporte de derivados. Destaca-se o crescimento desordenado, com habitações de médio e baixo padrão construtivo e presença de bolsões de pobreza. Esse processo pressiona a infraestrutura de abastecimento de água, esgotamento sanitário e captação de lixo, provocando o surgimento de doenças como esquistossomose, dengue e leishmaniose, além da proliferação de doenças sexualmente transmissíveis.

0 refino, armazenamento e transporte do petróleo e derivados poderão contaminar o ambiente e degradar os ecossistemas locais, já modificados pela expansão da policultura, retirada de madeira, expansão imobiliária desordenada, aterramento para construções, instalação de viveiros, pesca predatória, poluição dos estuários com consequentes impactos na fauna eflora ${ }^{24}$. A implantação da refinaria está removendo extensões de áreas de mangue, contribuindo para a degradação ambiental ${ }^{25}$.

Quanto à infraestrutura viária, a deficiência na capacidadee qualidade das rodovias será agravada pelo intenso trânsito de veículos nas fases de implantação e operação da refinaria, e os gases liberados pelos veículos terão impacto na qualidade do ar. 0 trânsito intenso incrementará a morbidade e a mortalidade na região em decorrência deacidentes, além de contribuir para a prostituição, disseminação de doenças sexualmente transmissíveis e exploração infantil.

Segundo Samaja $\mathrm{a}^{14,16}$, os problemas do desenvolvimento humano são inseparáveis dos ambientes de desenvolvimento social das populações envolvidas e inseparáveis dos problemas da re produção social. Essa concepção foi adequada aos objetivos de analisar os cenários de risco envolvidos no refino de petróleo no contexto de uma região no Nordeste do Brasil. Dada a complexidade dos problemas para a saúde e 0 ambiente, as ações em vigilância da saúde devem ser amparadas por um modelo integrado facilitador de ações intersetoriais, interdisciplinares e participativas, possibilitando uma abordagem ecossistêmica em contraposição à tradicional fragmentação em atendimento aos problemas decorrentes de empreendimentos da envergadura de uma refinaria de petróleo.

Para assegurar à população um ambiente com qualidade de vida e saúde, para instalação de obra ou atividade potencialmente causadora designificativa degradação do ambiente, se exige estudo prévio deimpacto ambiental (EIA $)^{28}$, cujo resultado origina o Relatório de Impacto Ambiental (RIMA), que deverá ser divulgado e submetido à consulta pública²9.

Os EIA/RIMA da REFINE contemplam aspectos de descrição do projeto (volumel); diagnóstico ambiental (volumes II, III, IV) eidentificação e análise de impactos; avaliação da compatibilidade com planos, projetos e programas do governo; avaliação de alternativas locais e tecnológicas; medidas mitigadoras e compensatórias; acompanhamento e monitoramentos (volume V). Todavia, apresentam uma análise parcial e fragmentada da realidade, consequente à ausência de elementos contextuais de condições de saúde e sustentabilidade socioambiental.

As avaliações de impacto ambiental feitas no EIA/RIM A selimitam aos ambientes físico ebiológico, não incluindo em seu escopo os possíveis impactos à saúde e os aspectos de proteção, demonstrando a fragilidade das análises.

O EIA/RIM A não apresenta estudo da qualidade do ar, limitando-se a afirmar que no CIPS os poluentes atmosféricos estão dentro dos limites estabelecidos pela Resolução CON AM A n 03/90. $N$ ão constam os poluentes secundários, tais como o ozônio, resultantes de reações químicas que ocorrem na atmosfera e onde participam alguns poluentes primários produzidos pela refinaria; e não foi previsto o cálculo de emissão das fontes de poluição atmosférica. Isso dificultará a prevenção e a compensação das taxas de emissão de poluentes atmosféricos liberados pela refinaria ou gerados a partir dos poluentes primários, bem como a diferenciação dos impactos por empresa.

0 projeto da refinaria não prevê sistema de tratamento adequado para remoção demetais pesados, limitando-se a drenagens dos tanques de armazenamento, e não há projeto para tratamento de resíduos como a soda gasta, gerada a partir do tratamento da gasolina. Em relação ao tratamento e destinação final dos resíduos sólidos gerados na fase de operação, as informações são superficiais, sendo informado apenas que os mesmos serão coprocessados junto a outras indústrias.

As limitadas medidas mitigadoras propostas para os impactos esperados e a negação da incomensurabilidade dos valores ambientais em ambas as análises mostram a insuficiência da abordagem dada ao complexo problema socioambiental resultante da instalação da REFINE e criam uma perspectiva de impactos negativos sobre a saúde, em particular a dos trabalhadores. 
Procurando suprir essas deficiências, Cancio ${ }^{13}$ propõe uma matriz para analisar os EIA/RIM A, considerando categorias analíticas e operacionais que permitem uma abordagem complexa, na medida em que envolve os conceitos de vulnerabilidade, riscos ambientais, acidentes am pliados, acidentes de trabalho, território, fluxos migratórios, entre outros. Essa metodologia poderia ser aplicada para empreendimentos como a REFINE.

\section{Consideraçõesfinais}

As refinarias de petróleo representam um investimento produtivo potencialmente degradante e a crescente gravidade dos riscos tecnológicos da indústria petroquímica, aliada aos complexos contextos sociais, econômicos, ambientais e políticos em que se insere a refinaria no Estado de Pernambuco, pode resultar em impactos sobreo ambiente ea saúde das populações. Esses impactos atingem negativamente a economia local e promovem a inutilização de regiões turísticas. N esse sentido, o modelo dedesenvolvimento precisa incorporar a preocupação com a sustentabilidade ecológica e social.

A implantação da REFINE nesse território desconsidera a sustentabilidade socioambiental, na medida em que pode deteriorar as condições de vida da população e dos trabalhadores, promovendo a apropriação dos recursos ambientais com exportação de riscos entre regiões e a concentração de renda e poder. Sua localização em Suape foi influenciada pela chantagem locacional, conhecida como a associação entre fracas atuações política e social voltadas ao controle da poluição e das injustiças sociais, eque, no Brasil, é responsável por migração de indústrias extremamente poluidoras, de áreas onde há maior organização social para áreas mais pobres ${ }^{30}$.

A forma como as leis e normas relativas à gestão ambiental são elaboradas e implementadas na região geram um conflito de competência, em que os papéis dos órgãos gestores ou dos diversos atores sociais não estão claramente definidos ou se sobrepõem. Até o momento, não há um Sistema dePlanejamento eG Gãão U rbana e Ambiental que considere a integração regional baseado na sustentabilidade.

As medidas econômicas fal ham ao considerar como externalidade a poluição ambiental. Desta forma, a sociedade, enão o contaminador, é que suporta a carga e o custo de enfrentar os prejuízos sociais, econômicos e ambientais. Destaca-seainda a dificuldade deestabelecer nexo de causalidade entre a exposição e os efeitos na saúde dos trabal hadores e da população.

Esse novo cenário industrial vai exigir um sistema de vigilância à saúde articulado intersetorialmente, com participação e fortalecimento das organizações sociais, capaz de atuar sobre os riscos e evitar o adoecimento dos trabalhadores e da população no entorno do empreendimento. Essas ações de vigilância devem ser guiadas pelo princípio da precaução, entendido como o reconhecimento antecipado dos riscos e contextos nocivos à saúde, ou seja, a intervenção deveocorrer antes do acontecimento de eventos nocivos e não apenas agir sobre esses, enfatizando a promoção da saúde e a prevenção de riscos.

A construção da matriz de dados com base na reprodução social possibilitou identificar variáveis importantes para a construção de indicadores voltados à vigilância da saúde ambiental, uma vez que permite identificar mudanças significativas nas configurações das condições de saúde e do ambiente, antecipando nocividades e subsidiando o planejamento de ações futuras, orientado por atitudes precaucionárias, tanto para as redes sociais como institucionais.

As ações de vigilância devem focar os ambientes ou contextos onde se desenvolvem os processos reprodutivos da vida social, sendo responsável pela observação das mudanças significativas ocorridas nas condições de vida da população, que contribuem para transformar a situação de saúde, antecipando a direção dessas modificações.

Compreende-se que a promoção da saúde do trabalhador, assim como a de toda população, depende da qualidade do ambiente e dos model os de produção em que estes indivíduos se encontram. Desta forma, pensar em qualidade de vida implica defender modalidades de desenvolvimento sustentável, que enfrentem as crises de desenvolvimento social e ambiental, buscando condições suportáveis de crescimento.

\section{Colaboradores}

Todos os autores participaram da concepção e do delineamento da pesquisa. A autora AM Gurgel escreveu a primeira versão do artigo, a qual recebeu contribuições dos outros autores. Todos os autores revisaram e aprovaram a versão final. 


\section{Referências}

1. Porto MF. Saúde, ambiente e desenvolvimento: reflexões sobre a experiência da COPASAD - Conferência Pan-americana de Saúde e Ambiente no Contexto do Desenvolvimento Sustentável. Cien Saude Colet 1998; 3(2):33-46.

2. Mariano JB. Impactos ambientais do refino de petróleo [dissertação]. Rio de Janeiro (RJ): Universidade Federal do Rio de Janeiro; 2001.

3. Campbell JC, Laherrère JH. The End of Cheap Oil. Scientific American 1998; 276(3):78-83.

4. International Energy Agency. Analysis of the impact of high oil prices on the global economy. 2004. [acessado 2009 fev 1]. Disponível em: http://www.iea.org/ Textbase/Papers/2004/High Oil Prices.pdf

5. Vieira FCS. Toxicidade de Hidrocarbonetos M onoaromáticos do Petróleo sobre M etamysidopsis elongata atlantica (Crustacea: M ysidacea) [tese]. Florianópolis (SC): Universidade Federal de Santa Catarina; 2004.

6. Petróleo Brasileiro S/A. Diretoria Aprova Refinaria no N ordeste com PDVSA. [site na Internet]. [acessado 2008 fev 10]. Disponível em: http://www2.petrobras. com.br/ri/spic/bco_arq/2494_pdvsa_final.pdf

7. Pires Advogados \& Consultores $S / C$. Estudo de Impacto Ambiental (EIA) de SUAPE/CIPS. vol. I. Recife: $\mathrm{CPRH} ; 2000$.

8. Augusto LGS. Estudo das alterações morfológicas (medula óssea) em portadores de neutropenia secundária à exposição ao benzeno [dissertação]. Campinas (SP): Faculdade de Ciências M édicas, Universidade Estadual de Campinas; 1991.

9. Kayal S, Connell DW. Polycyclic aromatic hydrocarbons in biota from the Brisbane River Estuary, Australia. Estuar. Coast. Shelf. Sci. 1995; 40:475-493.

10. M oreno FN, Corseuil HX. Fitorremediação de aquíferos contaminados por gasolina. Eng Sanit Amb 2001; 6:1-7.

11. Augusto LGS. Exposição ocupacional a organoclorados em indústria química de Cubatão - Estado de São Paulo: avaliação do efeito clastogênico pelo Teste de M icronúcleos [tese]. Campinas (SP): Faculdade de Ciências M édicas, Universidade Estadual de Campinas; 1995.

12. Freitas, CM, Porto M FS, Gomez CM. Acidentes químicos ampliados: um desafio para a saúde pública. Rev. Saude Publica 1995; 29(6):503-514.

13. Cancio JA. Inserção das questões de saúde no estudo de impacto ambiental [dissertação]. Brasília (DF): Universidade de Brasília; 2008.

14. Samaja JA. M uestra e representatividad em vigilância epidemiológica mediante sítios centinelas. Cad Saude Publica 1996; 12(3):309-319.

15. Augusto LGS, Florêncio L, Pontes CAA. U ma nova compreensão da causalidade e dos métodos de investigação em Saúde Ambiental. In: Augusto LGS, Florêncio L, Carneiro RM, organizadores. Pesquisa(ação) em Saúde Ambiental: contexto, complexidade, compromisso social. 2a ed. Recife: Editora Universitária da UFPE; 2005. p. 19-27.

16. Samaja JA. A reprodução social e a saúde: elementos teóricos e metodológicos sobre a questão das relações entre saúde e condições de vida. Salvador: Ed. ISCUFBA/Casa da Saúde; 2000.
17. Augusto LGS, Carneiro RM, Costa AM. Vigilância Ambiental: um novo conceito uma nova abordagem. In: Augusto LGS, Florêncio L, Carneiro RM, organizadores. Pesquisa(ação) em Saúde Ambiental: contexto, complexidade, compromisso social. 2a ed. Recife: Editora Universitária da UFPE; 2005. p. 31-38.

18. Petróleo Brasileiro S/A. Sonho Concretizado. PETROBRAS M agazine [periódico na Internet]. 2007 [acessado 2008 fev 10]. Disponível em: http:// www2. petrobras.com.br/Atuacaol nternacional/PetrobrasM agazine/pm48/port/sonho 3.html

19. PETROBRAS/FADE. Relatório de Impacto Ambiental - RIM A. Recife: Refinaria do N ordeste S.A., 2006.

20. Santi AM M. Co-incineração e co-processamento de resíduos industriais perigosos em fornos de clínquer: Investigação no maior pólo produtor de cimento do País, Região M etropolitana de Belo Horizonte, M G, sobre os riscos ambientais, e propostas para a Segurança Química [tese]. Campinas (SP): Universidade Estadual de Campinas; 2003.

21. M onteiro RTR. Principais processos poluidores - ecossistemas terrestres, aquáticos e atmosféricos. São Paulo: Centro de Energia Nuclear na Agricultura/USP; 2005. [M imeo]

22. Freitas CM, Porto M FS, M achado JMH. A cidentes Industriais ampliados: desafios e perspectivas para 0 controle e a prevenção. Rio de Janeiro: Fiocruz; 2000.

23. De M artini Junior LCA. Comunicação de Riscos na Emergência. Revista Saneamento Ambiental 1998; 49:46-50.

24. Agência Estadual de Planejamento e Pesquisas de Pernambuco. Território Estratégico de Suape - Diretrizes para uma ocupação sustentável. Recife: CONDEPE/FIDEM ; 2006.

25. Ramos MHA, M elo ASSA, Ramos FS. A implantação de uma refinaria de petróleo em SUAPE-PE: uma avaliação dos impactos sócio-econômico-ambientais a partir da interpretação de Agendas 21 Locais. [acessado 2009 fev 07]. Disponível em: http://www.ecoeco. org.br/conteudo/publicacoes/encontros/vii_en/ mesa2/trabalhos/uma avaliacao qualitativa dos impactos_da_implantacao_de_uma_refinariā.pdf

26. Instituto Brasileiro de Geografia e Estatística. Censo Demográfico 2000. Rio de Janeiro; IBGE; 2001.

27. Agência Estadual de Planejamento e Pesquisas de Pernambuco. Base de dados do Estado. 2002. [acessado 2008 ago 1]. Disponível em: http://www.bde.pe.gov.br

28. Brasil. Constituição da República Federativa do Brasil. Brasília: Senado Federal; 1988. 29.

29. Agostinho M M. Responsabilidades da indústria do gás natural pelos danos causados ao meio ambiente. Jus N avigandi [periódico na Internet]. 2005 [acessado 2008 jul 23]. Disponível em: http://jus2.uol. com.br/doutrina/texto.asp?id $=6256$

30. Câmara VM, Tambellini AT, Castro HA, Waissmann W. Saúde Ambiental e Saúde do Trabalhador: Epidemiologia das relações entre a produção, 0 ambiente e a saúde. In: Rouquayrol MZ, Almeida Filho N. organizadores. Epidemiologia \& Saúde. 6a ed. Rio de Janeiro: MEDSI; 2003. p. 469-497.

Artigo apresentado em 10/06/2009

Aprovado em 21/08/2009

Versão final apresentada em 31/08/2009 